\title{
A TEORIA DE JUSTIÇA DE JOHN RAWLS E AS AÇÕES AFIRMATIVAS DEFENDIDAS PELA DEFENSORIA PÚBLICA
}

\author{
Emanuel Adilson Gomes Marques ${ }^{1}$ \\ Adriana Silva Maillart ${ }^{2}$
}

\section{RESUMO}

Esta pesquisa tem por escopo analisar as ideias de justiça de John Rawls, visando demonstrar seus ideários privilegiam o Estado Democrático de Direito, como essenciais à inclusão e diminuição das desigualdades materiais que vai ao encontro da missão da Defensoria Pública brasileira. Assim, objetiva demonstrar que a atuação da Defensoria Pública, por meio de ações afirmativas adotadas em políticas públicas, atinge os ditames de justiça proposto na Teoria de Rawls. Este estudo apoia-se no método dedutivo de abordagem e nas técnicas de pesquisa documental e bibliográfica.

Palavras-chaves: Teoria de Justiça; John Rawls; Ações Afirmativas; Defensoria Pública.

\section{THE THEORY OF JOHN RAWLS JUSTICE AND AFFIRMATIVE ACTION DEFENDED BY PUBLIC DEFENDER}

\begin{abstract}
This research analyzes the John Rawls' theory of Justice, seeking to demonstrate their ideals privilege the democratic rule of law as essential to inclusion and reduction of material inequalities that meets the mission of the Brazilian Public Defender. Thus, it aims to demonstrate that the performance of the Public Defender, through affirmative actions taken in public policy, achieves justice dictates proposed in Rawls's theory. This study relies on deductive method of approach and the documentary and bibliographic research techniques.
\end{abstract}

\section{Keywords:}

Theory of Justice; John Rawls; Affirmative Actions; Public Defender;

\section{INTRODUÇÃO}

No presente ensaio pretende-se analisar a Teoria de Justiça de Rawls como fundamento da atuação da Defensoria Pública, objetivando demonstrar que a Instituição Defensoria Pública tem a função de atuar coletivamente, com adoção de ações

\footnotetext{
${ }^{1}$ Mestrando em Direito pela Universidade Nove de Julho. Pós Graduado em Direito Público pela Centro Universitário Izabela Hendrix, Pós Graduado em Direito Civil e Processo Civil pela Universidade Gama Filho. Defensor Público Federal - SP. Membro do GT - LGBTI da Defensoria Pública da União. Email: emanuel.marques@dpu.def.br

${ }^{2}$ Mestre e doutora em Direito pela Universidade de Santa Catarina, com parte de sua pesquisa realizada na Universidad de Valéncia, Espanha. Professora do corpo permanente e pesquisadora do programa de Mestrado da Universidade Nove de Julho (UNINOVE). Coordenadora do Curso de Direito da mesma Instituição.
} 
afirmativas, voltadas a implementação de igualdade material, promovendo estabelecer diferenças em prol da inclusão social.

Diante dos dados estatísticos de aumento da pobreza e da extrema miséria no Brasil, faz-se necessário que nova teoria de base, seja utilizada com objetivo de eliminação das desigualdades entre os seres humanos. Entretanto, pergunta-se: o que é uma sociedade justa? Existe um conflito permanente entre os bens disponíveis, que são escassos e o desejo ilimitado de posse por parte dos indivíduos. Será que Rawls responde a tais indagações? Será que a Teoria da Justiça de Rawls é, ao mesmo tempo, cuidadosa com o valor da liberdade em convivência com o valor da igualdade?

$\mathrm{O}$ mencionado autor cria uma teoria de Justiça que agrega os dois principais valores do mundo moderno: os valores da liberdade e da igualdade. As grandes ideologias do Séc. XX tornaram estes dois grandes valores que colidem e são dificilmente conjugados. Um dos grandes desafios é responder ao questionamento de Justiça, bem como estruturar Instituições capazes de promover a devida implementação.

Para isso, inicialmente apresentaremos os argumentos rawlsianos que fundamentam seu foco na estrutura básica de justiça. Em seguida analisar-se-á se a referida doutrina pode ser parâmetro para atuação da Defensora Pública no Estado Democrático de direito.

Este estudo apoia-se no método dedutivo de abordagem e nas técnicas de pesquisa documental e bibliográfica.

\section{PENSAMENTO FILOSÓFICO JOHN RAWLS}

John Rawls foi filósofo norte-americano das Universidades de Oxford e Havard, nascido em 1921 e falecido em 2002. Referido autor estruturou conceito de Justiça como um conjunto vasto da atividade humana, consistente nas Instituições Políticas, os sistemas jurídicos e as formas de organização social. Em sucintos termos, para ele, a função da Justiça é a de definir atribuição de direitos e deveres e de distribuir encargos e benefícios de cooperação social.

A teoria de John Rawls fundamentou o liberalismo e a moral nos direitos da pessoa e no contrato social, mostrando-se uma alternativa às posições utilitaristas da época. Isso porque, como ressalta o próprio Rawls, ao contrário do utilitarismo, que adota para a sociedade o princípio da escolha racional, não levando em consideração a distinção 
entre as pessoas (VITA, 1992, p. 6), a sua teoria vê os cidadãos como "pessoas [...] detentoras de necessárias capacidades de personalidade moral que as habilitem a participar da sociedade vista como um sistema de cooperação justa para o benefício mútuo" (RAWLS, 1992, p. 28-30).

John Rawls utiliza os pensamentos históricos do século XVIII para o século XX, as transformações do mundo moderno e contemporânea, constituindo-se seu pensamento a partir das grandes teorias de outros pensadores. Três pressupostos básicos fundamentais se destacam para entender a sua teoria da justiça como equidade.

O primeiro pressuposto para a construção da sua teoria é a escassez moderada dos recursos. A totalidade dos bens distribuídos é menor que a demanda. Situando-se no século $\mathrm{XX}$, temos que partir deste reconhecimento. $\mathrm{O}$ desejo ilimitado de posse e a limitalidade dos bens. A natureza não está para prover recursos infinitamente, embora os desejos sejam ilimitados.

Um segundo pressuposto da sua teoria é o reconhecimento do pluralismo. Ou seja, a existência de um desacordo profundo entre as concepções de bem defendida pelos indivíduos e grupos que compõe uma sociedade moderna. Existem pluralismo de formas de vida, não se comungando de uma doutrina compartilhada por todos. Há uma ruptura de entender a política clássica e a política moderna. Na política clássica identificava-se o bem supremo, e a forma de organização política melhor conduziria a forma de excelência da vida humana. Tal forma de conceber o mundo era compartilhado desde Platão, Aristóteles, os Estoicos, pelos Epicuristas, pensadores Medievais (Santo Agostinho e São Tomás de Aquino). A política clássica era pensada na concepção de um bem supremo que que norteia a vida do indivíduo. A vida política é o modo excelente na qual os homens aspiram. Cite-se o modelo da cidade de Deus, na visão de Santo Agostinho. Grandes pensadores que melhor estruturam tal pensamento foram Maquiavel e Hobbes (HOBBES, 1998, p. 36). A filosofia política moderna tem como função fundamental, a ideia do estabelecimento de princípios de justiça que regulam a vida em comum, de forma a propiciar a liberdade e a igualdade durante a existência. Rawls afirma que, em matéria referente à dignidade da vida humana, a concepção de bem, a tendência é divergir a convergir. Ou seja, a capacidade de liberdade dos indivíduos tende a criar estilos cada vez mais diferenciados, objetivando a existência digna. 
O terceiro pressuposto é o reconhecimento de todos os membros da sociedade como indivíduos racionais e razoáveis. Noutras palavras, indivíduos capazes de formular uma concepção do bem e de desenvolver um senso de justiça. Ser racional, é ser capaz de escolher fins, metas, dotar-se dos meios mais eficazes para atingi-lo.

Rawls parte de uma concepção geral de Justiça que se baseia na ideia de que todos os bens sociais primários, tais como liberdades, oportunidades, riqueza e rendimentos, devem ser distribuídos de maneira igual a menos que uma distribuição desigual de alguns ou de todos estes bens, beneficie os menos favorecidos.

A ideia inicial de Rawls é a de que a justiça deve ser objeto de um consenso de pessoas livres e racionais em uma posição de igualdade de direitos e jurisdição política.(RAWLS, 2005, p. 258-259).

Daí a criação dos dois princípios de justiça por John Rawls; da igual liberdade e da desigualdade social e econômica. Este último princípio se divide em princípio da diferença e princípio da igualdade equitativa das oportunidades. John Rawls, com o intuito de determinar a prioridade de um princípio com relação ao outro, criou a denominada cláusula de ordem léxica ou serial, que determina que o princípio de igual liberdade é estritamente prioritário em relação ao segundo princípio. E o princípio da igualdade equitativa das oportunidades é prioritário com relação ao princípio da diferença. Esses princípios podem ser traduzidos da seguinte forma e devem ser satisfeitas pelas instituições sociais:

1) toda pessoa tem um direito igual a um sistema plenamente adequado de liberdades fundamentais iguais que seja compatível com um sistema similar de liberdades para todos; e 2) as desigualdades sociais e econômicas devem satisfazer duas condições: a) a primeira é que devem estar vinculadas a cargos e posições abertos a todos em condições de igualdade equitativa de oportunidades; b) a segunda é que devem redundar no maior benefício possível para os membros menos privilegiados da sociedade (princípio da diferença) ${ }^{3}$.

\footnotetext{
${ }^{3}$ Cecília Caballero Lois chama atenção para o fato de que este segundo princípio possui relevância, pois é por meio dele que, primeiramente, Rawls explica o seu liberalismo, ou seja, a opção injustificada da liberdade como princípio primordial de seu sistema de justiça, buscando construir uma sociedade sem barreiras sociais. E, ainda, complementa que "o segundo princípio impõe a igualdade de oportunidades (educação, cultura, trabalho, entre outras) e está intimamente relacionado com o primeiro. O que o autor tem em mente, neste momento, é o fato de que, quando as condições materiais são desfavoráveis, o valor dado à liberdade está prejudicado. Mas, quando as necessidades sociais estão desfavoráveis, o seu valor aumenta". LOIS, Cecilia Caballero. Uma teoria da constituição: justiça, liberdade e democracia em John Rawls. 2001. 370 f. Tese (Doutorado em Direito) - Centro de Ciências Jurídicas, Universidade Federal de Santa Catarina, Florianópolis, 2001, p. 180.
} 
$\mathrm{O}$ autor estrutura os aludidos princípios em ordem prioritária, ou seja, atendido o primeiro, parte-se para o segundo e assim sucessivamente, de forma que se aplica o posterior apenas quando satisfeito o anterior.

John Rawls, explicando o princípio da diferença, expõe que esse princípio consiste na ideia de que "os naturalmente favorecidos não se devem beneficiar simplesmente porque são mais bem-dotados, mas apenas para cobrir os custos de treinamento e educação e para usar os seus dotes de maneira que ajudem também os menos favorecidos" (RAWLS, 2005, p. 66). John Rawls deixa claro, entretanto, que

\begin{abstract}
todos os valores sociais - liberdade e oportunidade, renda e riqueza, e as bases sociais da auto-estima - devem ser distribuídos igualitariamente a não ser que uma distribuição desigual de um ou de todos esses valores traga vantagens para todos. A injustiça, portanto, se constitui simplesmente de desigualdades que não beneficiem a todos (RAWLS, 2005, p. 66).
\end{abstract}

John Rawls ainda ressalta que o principal objetivo do princípio da diferença é estabelecer as bases da fraternidade e da cooperação social (RAWLS, 2005, p. 180).

A concepção liberal-igualitária tem por finalidade conciliar os ideais de liberdade e de igualdade ${ }^{4}$, combinando igual respeito a todas as concepções "racionais" da "vida boa", que andam lado a lado em nossas sociedades pluralistas, e a preocupação imparcial de garantir a cada cidadão o que lhe é necessário para procurar obter a realização de sua concepção da "vida boa" (ARNSPERGER, CHRISTIAN; VAN PARIJS, 2003, p - 68). Essa teoria compreende, portanto, a ideia da sociedade como um sistema equitativo de cooperação ${ }^{5}$ entre pessoas livres e iguais ${ }^{6}$.

\footnotetext{
${ }^{4}$ Celia Lessa Kerstenetzky, comentando os fins de liberdade e igualdade das pessoas, explica que "as pessoas iriam desejar ser livres para perseguir os fins que porventura viessem a possuir, e também iriam querer que estes fins, quaisquer que fossem, possuíssem para a sociedade um valor igual, inspirando, portanto, um respeito igual". KERSTENETZKY, Celia Lessa. Desigualdades Justas e igualdade complexa. Lua Nova: Revista de Cultura e Política. n. 47, 1999, p. 14.

${ }^{5}$ Essa cooperação, por sua vez, também possui algumas características bem definidas, como expõe o próprio Rawls (Justiça como eqüidade: uma concepção política, não metafísica, p. 35-36): 1. Ela é distinta de uma atividade socialmente coordenada, por exemplo, por ordens emanadas de uma autoridade central. Pelo contrário, ela "é guiada por normas e procedimentos publicamente reconhecidos, que são aceitos pelos que cooperam como normas e procedimentos que regulam apropriadamente suas condutas". 2. A cooperação envolve a idéia de termos eqüitativos de cooperação, que cada participante pode razoavelmente aceitar, contanto que todos os demais também os aceitem. 3. Ela requer uma idéia da vantagem racional, ou bem, de cada participante; sendo que essa idéia de bem aponta aquilo que os envolvidos na cooperação estão tentando alcançar, quando o esquema é avaliado de seu ponto de vista.

${ }^{6}$ Segundo John Rawls (Justiça como eqüidade: uma concepção política, não metafísica, p. 37), "a idéia intuitiva básica é a de que, em virtude do que podemos chamar suas capacidades morais, e das capacidades da razão - o pensamento e o juízo, associados a essas capacidades - dizemos que as pessoas são livres. E
} 
Para John Rawls, os cidadãos são considerados livres quando capazes de assumir a responsabilidade por seus fins. Assim, “dadas instituições básicas justas e dado para cada pessoa um montante eqüitativo de bens primários [...], supõe-se que os cidadãos sejam capazes de ajustar seus fins e aspirações à luz daquilo com que podem razoavelmente arcar" (RAWLS, 2005, p. 49). Dentro dessa perspectiva, John Rawls propõe as exigências da justiça em termos de bens primários ${ }^{7}$, distinguindo os bens primários naturais, como saúde e os talentos, e bens sociais, estes últimos divididos em três categorias: liberdades fundamentais, acesso às diversas posições sociais e as bases sócias do respeito de si. Para John Rawls, o bem primário principal é o auto-respeito ou a auto-estima.

Isso acontece porque o liberalismo igualitário não interfere no modo em que os indivíduos devem viver suas vidas, não fornecendo preceitos para a conduta individual, a não ser quando essa conduta se refere às injunções que decorrem do "dever natural de justiça” (VITA, 1992, p. 279).

Esse "dever natural de justiça", por sua vez, compreende "a exigência que cada um faça o que se espera de si em instituições cujos princípios e normas constitutivos poderiam receber o assentimento de todas as pessoas que se dispusessem a chegar a um acordo em termos razoáveis" (VITA, 1992). Apesar de os indivíduos terem que se adequar às exigências de imparcialidade, que recaem diretamente sobre a justificação de princípios para a estrutura básica da sociedade e indiretamente sobre a conduta individual, a autonomia para viver sua própria vida de acordo com sua própria concepção de bem é permitida e até apoiada (VITA, 1992). Contudo, essa autonomia não deve ser confundida com a autonomia individual. Uma concepção de bem como autonomia individual para o liberalismo igualitário enfatiza a capacidade de a pessoa escolher seus próprios fins. Não

em virtude de possuírem essas capacidades em grau necessário a que sejam membros plenamente cooperativos da sociedade, dizemos que as pessoas são iguais".

${ }^{7}$ Para John Rawls (Uma teoria da justiça, p. 470), "bens são aquelas atividades e finalidades que têm as características, não importando quais sejam, que lhes conferem um lugar importante, até mesmo central, em nossa vida". Segundo Álvaro de Vita (2000, p. 239-240), citando classificação de Elster, "existem três tipos de bens que são relevantes para uma teoria da justiça distributiva: bens que são passíveis de distribuição, tais como a renda, a riqueza, o acesso a oportunidades educacionais e ocupacionais e a provisão de serviços; bens que não podem ser distribuídos diretamente, mas que são afetados pela distribuição dos primeiros, tais como o conhecimento e o auto-respeito; e bens que não podem ser afetados pela distribuição de outros bens, tais como as capacidades físicas e mentais de cada pessoa. A teoria de Rawls tem implicações claras para os dois primeiros tipos de bens. A realização dos princípios de justiça pela estrutura básica da sociedade cria as 'bases sociais' do auto-respeito, que Rawls entende ser o bem primário mais importante". 
são os fins dos agentes que são considerados valiosos, mas sim a capacidade do agente de escolhê-los (VITA, 1992).

Para que sua teoria tenha sustentação teórica, Rawls parte da argumentação de que pessoas livres, racionais, em uma posição de igualdade, definiriam as regras dos princípios de Justiça. Em virtude disso, ele menciona o véu da ignorância, contrapondose ao Estado da Natureza, uma vez que naquele estado existe um afastamento do ser humano dos seus instintos, fazendo com que as regras de equidade a serem futuramente implementadas, sejam justas.

Destarte, ao escolher princípios de justiça, as pessoas por trás do véu da ignorância buscarão garantir que tenham o maior acesso possível a esses bens distribuídos por instituições sociais. Ademais, considerando as circunstâncias do véu da ignorância, tais escolhas não serão pautadas pelo egoísmo, mas sim pela benevolência.

Disso decorre a necessidade de se efetivar uma configuração equitativa do procedimento na posição original que seja apto a conduzir a deliberação entre as partes a um resultado justo.

Portanto, o véu da ignorância serve de artifício teórico que busca assegurar as condições para a delimitação da noção mais imparcial possível de justiça. É uma situação em que "ninguém sabe qual é o seu lugar na sociedade, a sua posição de classe ou o seu status social (RAWLS, 2002, p. 147)".

\section{2 - PRINCÍPIO DA JUSTIÇA DE RAWLS}

Conforme anteriormente mencionado, o segundo princípio de Justiça da teoria rawlsiana está atrelada às desigualdades sociais e econômicas que devem atender as duas condições sendo que a primeira é que devem estar vinculadas a cargos e posições abertos a todos em condições de igualdade equitativa de oportunidades $e$ a segunda é que devem redundar no maior benefício possível para os membros menos privilegiados da sociedade.

Cecília Caballero Lois (2001, p. 180) chama atenção ainda para o fato de que este segundo princípio possui relevância, pois é por meio dele que, primeiramente, Rawls explica o seu liberalismo, ou seja, a opção injustificada da liberdade como princípio primordial de seu sistema de justiça, buscando construir uma sociedade sem barreiras sociais. E, ainda, complementa que “o segundo princípio impõe a igualdade de 
oportunidades (educação, cultura, trabalho, entre outras) e está intimamente relacionado com o primeiro. O que o autor tem em mente, neste momento, é o fato de que, quando as condições materiais são desfavoráveis, o valor dado à liberdade está prejudicado. Mas, quando as necessidades sociais estão desfavoráveis, o seu valor aumenta.

Nos dizeres de Rawls:

Todos os valores sociais, liberdades e oportunidades, renda e riqueza, e as bases sociais do auto-respeito, devem ser distribuídos de forma igual, a não ser que uma distribuição desigual de um ou de todos esses valores seja vantajosa para todos. ${ }^{8}$ E continua as desigualdades sociais e econômicas devem ser dispostas de modo a que [...] se estabeleçam para o máximo benefício possível dos menos favorecidos que seja compatível com as restrições do princípio de poupança justa. (RAWLS, 2002, p. 75)

Noutras palavras, para o referido autor as desigualdades socioeconômicas só serão aceitas caso acarretem benefícios aos mais desfavorecidos na ordem de distribuição dos recursos sociais disponíveis.

Na justiça como equidade a posição original de igualdade corresponde ao estado de natureza na teoria tradicional do contrato social. Essa posição original não é, obviamente, concebida como uma situação histórica real, muito menos como uma condição primitiva da cultura. É entendida como uma situação puramente hipotética caracterizada de modo a conduzir a uma certa concepção da justiça. Entre as características essenciais dessa situação está o fato de que ninguém conhece seu lugar na sociedade, a posição de sua classe ou o status social e ninguém conhece sua sorte na distribuição de dotes e habilidade naturais, sua Inteligência, força e coisas semelhantes. Eu até presumirei que as partes não conhecem suas concepções do bem ou suas propensões psicológicas particulares. Os princípios da justiça são escolhidos sob um véu de ignorância. Isso garante que ninguém é favorecido ou desfavorecido na escolha dos princípios pelo resultado do acaso natural ou pela contingencia de circunstancias sociais. Uma vez que todos estão numa situação semelhante e ninguém pode designar princípios para favorecer sua condição particular, os princípios da justiça são resultado de um consenso ou ajuste equitativo. A justiça como equidade começa, como já disse, com uma das mais genéricas dentre todas as escolhas que as pessoas podem fazer em conjunto, especificamente, a escolha dos primeiros princípios de uma concepção de justiça que deve regular todas as subsequentes críticas e reformas das instituições. Depois de haver escolhido um a concepção de justiça, podemos supor que as pessoas deverão escolher uma constituição e uma legislatura para elaborar leis, e assim, por diante, tudo em consonância com os princípios da justiça inicialmente acordados. RAWLS, 2002, p. 13-14. 
Neste aspecto defende-se as ações afirmativas, uma vez que para uma sociedade ser considerada justa é necessário a diminuição das diversas formas de desigualdades, impondo-se uma atuação em prol de minorias.

Tais políticas afirmativas consistem em instrumentos de inclusão social que erradicam ou, no mínimo mitigam desigualdades, garantindo-se aos cidadãos oportunidades e compensações que são causadas por motivos de miséria, pobreza, religião, gênero, etc.

Dados estatísticos comprovam que a miséria no Brasil cresce a cada dia. $\mathrm{O}$ conceito de miséria é estabelecido pelo decreto do "plano Brasil sem Miséria". Nele, a renda familiar de até $\mathrm{R} \$ 77$ por mês, per capita, é o limite da extrema pobreza no país. Por esta estimativa, os dados do Ipea mostram que a proporção de miseráveis, em relação a outras faixas, cresceu de 3,6\%, em 2012, para 4\% no ano de 2013.

Da mesma forma, podemos destacar que o problema da pobreza se tornou algo planetário. De acordo com o relatório 2014 da Organização das Nacções Unidas (ONU) sobre o Desenvolvimento Humano, cujo tema foi "Sustentar o Progresso Humano, reduzir as vulnerabilidades e reforçar a resiliência", observou-se que cerca de 1,2 mil milhões de pessoas vivem com menos de 1,25 dólares por dia, e 1,5 mil milhões vivem em situação de pobreza 9 .

Diante deste quadro, percebe-se que a pobreza é um problema fundamental e o seu combate, dentro da teoria de Rawls, deve ser tratado como relevante para efetivação da Justiça. Relevante mencionar que tal objetivo de justiça constitui um dos objetivos do Estado Democrático Brasileiro, de acordo com art. $3^{\circ}$, III da CF.

Com efeito, trata-se de grande desafio a erradicação da pobreza, devendo ocorrer verdadeira união de múltiplos sujeitos, com diferentes papeis para alcançar tal mister.

Não se olvide de que a pobreza é considerada pelos pesquisadores uma violação aos direitos humanos, ocorrendo verdadeira violação aos direitos civis, políticos e sociais.

\footnotetext{
${ }^{9}$ Pobreza multidimensional, cálculos do Gabinete do Relatório do Desenvolvimento Humano baseados em vários inquéritos a famílias, incluindo os Inquéritos sobre Demografia e Saúde da ICF Macro, os Inquéritos de Grupo para Indicadores Múltiplos do Fundo das Nações Unidas para a Infância (UNICEF) e vários inquéritos nacionais a agregados familiares; pobreza de rendimentos, cálculos do Gabinete do Relatório do Desenvolvimento Humano baseados em dados da base de dados Indicadores do Desenvolvimento Humano do Banco Mundial.
} 
Desta feita, a teoria de Rawls, no que se refere ao princípio da diferença, é plenamente aplicável às políticas públicas redistributivas no Brasil, favorecendo os menos favorecidos para a inclusão social.

Neste ínterim, ações afirmativas, objetivando planejar e atuar para a inclusão de determinadas pessoas, deve ser privilegiada, afigurando-se imprescindível cumprir o mandamento constitucionais para consecução de ações afirmativas inclusivas.

Manoel Gonçalves Ferreira Filho doutrina:

Sem dúvida, não há dificuldade em reconhecer que todos os seres humanos são iguais em natureza, portanto, em dignidade. Assim, todos são iguais quanto aos direitos fundamentais, vida, liberdade, igualdade, segurança e propriedade, como enumera o art. $5^{\circ}$, caput, da Constituição brasileira. Isso, porém, não exclui as diferenciações que levam em conta peculiaridades pessoais, como idade, sanidade mental, etc., como espelha o direito civil, sem que ninguém conteste sua compatibilidade com a igualdade. São diferenciações que respondem ao fato de que tais pessoas não estão, nos atos da vida, nas mesmas condições do ser humano que o direito toma como padrão de referência, ser humano este, no auge de sua vitalidade e plenamente são. Entretanto, colhem os seres humanos outras diferenças, que os desvantajam em face desse ser humano padrão. São as diferenças quanto a condições sociais, decorrentes de diferentes situações - culturais, econômicas, sociais, etc., em que aparecem na sociedade os seres humanos concretos, considerados nos grupos que integram. Tais diferenças são frequentemente de ordem coletiva, no sentido que refletem a posição do grupo sociais a que pertence o prejudicado - o discriminado enquanto membro do grupo desavantajado. Ora, pela lógica da Justiça, que manda dar tratamento desigual àqueles que entre si se desigualam, cabe tratamento diferenciado em favor destes. Um tratamento compensatório ou corretivo. É a discriminação reversa que pretende corrigir pelas ações afirmativas a discriminação em detrimento de grupos sociais (FERREIRA FILHO, 2003, p. 74-75).

A Ministra do STF, Carmen Lúcia Antunes Rocha sintetiza:

Somente a ação afirmativa, vale dizer, a atuação transformadora, igualadora pelo e segundo o Direito, possibilita a verdade do princípio da igualdade, para se chegar à igualdade que a Constituição Brasileira garante, como direito fundamental de todos. $\mathrm{O}$ art. $3^{\circ}$ traz uma declaração, uma afirmação e uma determinação em seus dizeres. Declarara-se, ali, implícita, mas claramente, que a República Federativa do Brasil não é livre, porque não se organiza segundo a universalidade desse pressuposto fundamental para o exercício dos direitos, pelo que, não dispondo todos de condições para o exercício de sua liberdade, não pode ser justa. Não é justa porque plena de desigualdades antijurídicas e deploráveis para abrigar o mínimo de condições dignas para todos. Não é solidária porque fundada em preconceitos de toda a sorte. $\mathrm{O}$ art. $3^{\circ}$ traz também uma afirmação: a de que, conquanto retratada a inexistência de uma autêntica República Democrática, o Direito organizou um modelo de Estado que se põe exatamente para realiza-la (ROCHA, 1996, p. 91). 
Assim, com a utilização de políticas públicas que adotem ações afirmativas como medidas excepcionais, estar-se-á propiciando a implementação da igualdade material constitucional, nos termos idealizados pela Teoria de John Rawls. A Constituição Federal Brasileira, em inúmeros artigos preconiza o nivelamento das desigualdades materiais, impondo-se uma postura positiva por parte do poder político para efetivá-las.

\section{A DEFENSORIA PÚBLICA E A TEORIA DE RAWLS}

Nesse sentido, adentra-se no aspecto da Defensoria Pública Brasileira como agente transformador da realidade social e implementação de direitos às minorias esquecidas.

Como cediço, a Defensoria Pública no Brasil foi criada com o intuito, dentre outras finalidades, de implementar políticas inclusivas cumprindo exatamente o que determina a Constituição Federal em seu art. $5^{\circ}$ que assegura: “Todos são iguais perante a lei, sem distinção de qualquer natureza, garantindo-se aos brasileiros e aos estrangeiros residentes no País, a inviolabilidade do direito à vida, à liberdade, à igualdade, à segurança e à propriedade." (BRASIL,2015) (grifa-se).

E no inciso LXXIV, que afirma: “O estado prestará assistência jurídica integral e gratuita aos que comprovarem insuficiência de recursos" (CF,1988). Quando se refere ao que não possui hipossuficiência de recursos, entenda-se, recursos financeiros, bem como insuficiência organizacional para implementação dos direitos de categorias que do ponto de vista estrutural são hipossuficientes.

Pode-se afirmar então, que a Defensoria Pública também é um meio pelo qual o indivíduo conhece e reconhece seus direitos, protegendo os desamparados e as minorias para que possam ser contemplados no ideal de Justiça proposto por Jown Ralws.

Resta-nos claro que a CF Brasileira optou por um sistema de assistência jurídica que tutele direitos das minorias. A Defensoria Pública tem como missão a orientação jurídica, a promoção dos direitos humanos e a defesa dos direitos individuais e coletivos, de forma integral e gratuita aos necessitados. 
No Brasil, a Defensoria Pública ganhou legitimidade Constitucional para promover a igualdade social, buscando o combate à pobreza e a inclusão de minorias. Contudo, questiona-se: será que as Defensorias Públicas estão efetivamente atuando contra a pobreza e marginalização e, em contrapartida, buscando a atuação de ações afirmativas que concretizem ideal de Justiça de John Rawls?

O instrumento que pode ser utilizado pela Defensoria para a implementação destes direitos será por meio de tutelas coletivas, tão sabiamente concedido pela Lei 11.448/2007, dando legitimidade para que o órgão proponha ações civis públicas em prol dos necessitados economicamente, bem como àqueles necessitados do ponto de vista organizacional. Conforme nos ensina Érik Palácio Boson:

\begin{abstract}
Isso significa dizer que, entendida a possibilidade jurídica de atuação pela Defensoria como um instrumento para a efetivação do próprio direito material, e considerando que o titular do direito protegido pela Instituição é um sujeito/grupo vulnerável, assegurar condições fáticas e jurídicas para a possibilidade real de atuação da Defensoria Pública significa, em proporção direta, proteger as pessoas mais vulneráveis. É esta inclusive a razão pela qual não se deve limitar, como insistem em fazer alguns desavisados, a atribuição da Instituição na defesa dos necessitados apenas no sentido de hipossuficiência econômica. Os contornos constitucionais dados à Defensoria Pública, bem assim as previsões contidas em sua respectiva Lei Orgânica, não permitem tal exegese minimalista. Ao revés, o que deve nortear a análise da atribuição da instituição é a ideia do exercício pleno da cidadania. Daí porque qualquer vulnerabilidade dá margem à atuação da instituição.(BOSON, 2016, p. 21).
\end{abstract}

Importante destacar que em maio de 2015 o Supremo Tribunal Federal, decidiu pela improcedência da ADI 3943, considerando, por unanimidade a atribuição da Defensoria Pública para propor Ação Civil Pública. A Ministra Carmen Lúcia, relatoria da referida ADI, destacou dentre outros aspectos, que o aumento de atribuições da instituição amplia o acesso à Justiça sendo perfeitamente compatível com a Lei Complementar 132/2009 e com as alterações à Constituição Federal promovidas pela Emenda Constitucional 80/2014, que estenderam as atribuições da Defensoria Pública e incluíram a de propor ação civil pública ${ }^{10}$.

${ }^{10}$ EMENTA: AÇÃO DIRETA DE INCONSTITUCIONALIDADE. LEGITIMIDADE ATIVA DA DEFENSORIA PÚBLICA PARA AJUIZAR AÇÃO CIVIL PÚBLICA (ART. $5^{\circ}$, INC. II, DA LEI N. 7.347/1985, ALTERADO PELO ART. $2^{\circ}$ DA LEI N. 11.448/2007). TUTELA DE INTERESSES TRANSINDIVIDUAIS (COLETIVOS STRITO SENSU E DIFUSOS) E INDIVIDUAIS HOMOGÊNEOS. DEFENSORIA PÚBLICA: INSTITUIÇÃO ESSENCIAL À FUNÇÃO JURISDICIONAL. ACESSO À JUSTIÇA. NECESSITADO: DEFINIÇÃO SEGUNDO PRINCÍPIOS HERMENÊUTICOS GARANTIDORES DA FORÇA NORMATIVA DA CONSTITUIÇÃO E DA MÁXIMA EFETIVIDADE DAS NORMAS CONSTITUCIONAIS: ART. $5^{\circ}$, INCS. XXXV, LXXIV, LXXVIII, DA CONSTITUIÇÃO DA REPÚBLICA. INEXISTÊNCIA DE NORMA DE 
É neste contexto que surge o papel primordial da Defensoria Pública implementar medidas capazes de proporcionar a implementação do princípio da igualdade, tratando iguais como iguais e desiguais como desiguais, no sentido Aristotélico.

Impõe-se que as Defensorias do Brasil realizem medidas capazes de concretizar o referido princípio, por meio de ações afirmativas que assim podem ser sintetizadas:

\begin{abstract}
Consistem em políticas públicas (e também privadas) voltadas à concretização do princípio constitucional da igualdade material e à neutralização dos efeitos da discriminação racial, de gênero, de idade, de origem nacional, de compleição física e situação socioeconômica (adição nossa). Impostas ou sugeridas pelo Estado, por seus entes vinculados e até mesmo por entidades puramente privadas, elas visam a combater não somente as manifestações flagrantes de discriminação, mas também a discriminação de fundo cultural, estrutural, enraizada na sociedade. De cunho pedagógico e não raramente impregnadas de um caráter de exemplaridade, têm como meta, também, o engendramento de transformações culturais e sociais relevantes, inculcando nos atores sociais a utilidade e a necessidade de observância dos princípios do pluralismo e da diversidade nas mais diversas esferas do convívio humano" (GOMES, 2001, p. 6-7).
\end{abstract}

O Supremo Tribunal Federal através do Leading Case n. ADPF 186/DF ${ }^{11}$, decidiu pela necessidade de se adotar políticas públicas voltadas à discriminação reversa,

EXCLUSIVIDAD DO MINISTÉRIO PÚBLICO PARA AJUIZAMENTO DE AÇÃO CIVIL PÚBLICA.
AUSÊNCIA DE PREJUÍZO INSTITUCIONAL DO MINISTÉRIO PÚBLICO PELO
RECONHECIMENTO DA LEGITIMIDADE DA DEFENSORIA PÚBLICA. AÇÃO JULGADA
IMPROCEDENTE. 11 ARGUIÇÃO DE DESCUMPRIMENTO DE PRECEITO FUNDAMENTAL. ATOS QUE INSTITUÍRAM SISTEMA DE RESERVA DE VAGAS COM BASE EM CRITÉRIO ÉTNICO-RACIAL (COTAS) NO PROCESSO DE SELEÇÃO PARA INGRESSO EM INSTITUIÇÃO PÚBLICA DE ENSINO SUPERIOR. ALEGADA OFENSA AOS ARTS. $1^{\circ}$, CAPUT, III, $3^{\circ}$, IV, $4^{\circ}$, VIII, $5^{\circ}$, I, II XXXIII, XLI, LIV, 37, CAPUT, 205, 206, CAPUT, I, 207, CAPUT, E 208, V, TODOS DA CONSTITUIÇÃO FEDERAL. AÇÃO JULGADA IMPROCEDENTE. I - Não contraria - ao contrário, prestigia - o princípio da igualdade material, previsto no caput do art. $5^{\circ}$ da Carta da República, a possibilidade de o Estado lançar mão seja de políticas de cunho universalista, que abrangem um número indeterminados de indivíduos, mediante ações de natureza estrutural, seja de ações afirmativas, que atingem grupos sociais determinados, de maneira pontual, atribuindo a estes certas vantagens, por um tempo limitado, de modo a permitir-lhes a superação de desigualdades decorrentes de situações históricas particulares. II - O modelo constitucional brasileiro incorporou diversos mecanismos institucionais para corrigir as distorções resultantes de uma aplicação puramente formal do princípio da igualdade. III - Esta Corte, em diversos precedentes, assentou a constitucionalidade das políticas de ação afirmativa. IV - Medidas que buscam reverter, no âmbito universitário, o quadro histórico de desigualdade que caracteriza as relações étnico- raciais e sociais em nosso País, não podem ser examinadas apenas sob a ótica de sua compatibilidade com determinados preceitos constitucionais, isoladamente considerados, ou a partir da eventual vantagem de certos critérios sobre outros, devendo, ao revés, ser analisadas à luz do arcabouço principiológico sobre o qual se assenta o próprio Estado brasileiro. V - Metodologia de seleção diferenciada pode perfeitamente levar em consideração critérios étnico-raciais ou socioeconômicos, de modo a assegurar que a comunidade acadêmica e a própria sociedade sejam beneficiadas pelo pluralismo de ideias, de resto, um dos fundamentos do Estado brasileiro, conforme dispõe o art. $1^{\circ}$, V, da Constituição. VI - Justiça social, hoje, mais do que simplesmente redistribuir riquezas criadas pelo esforço coletivo, significa distinguir, 
uma vez que cumpre a determinação constitucional de promoção de justiça social e igualdade material.

Desta feita, para possibilitar que a igualdade material entre as pessoas seja levada a efeito, o Estado pode lançar mão seja de políticas de cunho universalista, que abrangem um número indeterminado de indivíduos, mediante ações de natureza estrutural, seja de ações afirmativas, que atingem grupos sociais determinados, de maneira pontual, atribuindo a estes certas vantagens, por um tempo limitado, de modo a permitir-lhes a superação de desigualdades decorrentes de situações históricas particulares.

Como exemplo cita-se inúmeras ações promovidas pela Defensoria Pública da União objetivando a concessão do benefício assistencial do $\operatorname{LOAS}^{12}$ para idosos em deficientes que vivem em situação de miserabilidade no Brasil. Ressalte-se que, de acordo com dados estatísticos, somente até junho de $2016^{13}$ foram atendidas 872.757 (oitocentas e setenta e duas mil setecentas e cinquenta e sete) cidadãos, cujos pleitos, em sua maioria, dizem respeito a benefícios assistenciais.

Destaque-se que não se quer com isso somente dar algo de assistência a um grupo de indivíduos, mas de criar condições necessárias para que eles possam, por sua própria força, conquistar objetivos e cidadania. O que se pretende é implantar um estado igualitário e não assistencial.

Dentre outras demandas que objetivam implementar ideias de Justiça de Rawls, podemos citar ações também promovidas pela Defensoria Pública da União que tem por

reconhecer e incorporar à sociedade mais ampla valores culturais diversificados, muitas vezes considerados inferiores àqueles reputados dominantes. VII - No entanto, as políticas de ação afirmativa fundadas na discriminação reversa apenas são legítimas se a sua manutenção estiver condicionada à persistência, no tempo, do quadro de exclusão social que lhes deu origem. Caso contrário, tais políticas poderiam converterse benesses permanentes, instituídas em prol de determinado grupo social, mas em detrimento da coletividade como um todo, situação - é escusado dizer - incompatível com o espírito de qualquer Constituição que se pretenda democrática, devendo, outrossim, respeitar a proporcionalidade entre os meios empregados e os fins perseguidos. VIII - Arguição de descumprimento de preceito fundamental julgada improcedente.

12 A Lei Orgânica de Assistência Social (LOAS) ajudou de forma significativa o poder executivo, para que este implante as políticas necessárias que integradas ao trabalho das instituições assistenciais, diminuam as mazelas sociais. Art. $1^{\circ}$ A assistência social, direito do cidadão e dever do Estado, é Política de Seguridade Social não contributiva, que provê os mínimos sociais, realizada através de um conjunto integrado de ações de iniciativa pública e da sociedade, para garantir o atendimento às necessidades básicas. $\mathbf{V}-\mathbf{a}$ garantia de 1 (um) salário mínimo de benefício mensal à pessoa portadora de deficiência e ao idoso que comprovem não possuir meios de prover a própria manutenção ou de tê-la provida por sua família

13 Dados disponíveis em: Defensoria Pública da União. Quadro de assistidos. <http://www.dpu.gov.br/images/stories/transparencia/atendimento/Quadro_Atendimentos_Assistidos_Pro c_Judiciais_2016_JUN.pdf>. Acesso em: 20 set. 2016. 
metas permitir que cidadãos que estão vivendo nas ruas e albergues, possa realizar saques de FGTS e PIS. De fato, inexiste previsão legal para que a Caixa Econômica Federal proceda a liberação das referidas verbas, entretanto, diante da situação de penúria e extrema vulnerabilidade social e desigualdade, impõe-se a autorização do levantamento do montante.

\section{CONCLUSÃO}

Comparando a teoria de John Rawls com a Instituição Defensoria Pública, algumas conclusões se fazem imperiosas. Com efeito, pode-se afirmar que as leis e as políticas públicas devem ser reformadas caso não cumpram os mandamentos constitucionais, bem como o ideal de Justiça. Na teoria de Justiça de Rawls um aspecto não utilitarista, ou seja, busca-se parâmetros de equidade na implementação de Justiça, consubstanciada na igualdade material. As desigualdades econômicas e sociais devem ser distribuídas de tal forma que garantam os maiores benefícios possíveis aos menos favorecidos, propiciando a justa igualdade de oportunidades entre os indivíduos. As desigualdades eventualmente ocorridas devem privilegiar os que vulneráveis economicamente.

Neste ínterim, concorda-se com a abstração criada por Rawls, na qual extremamente necessário retirar o véu de ignorância e aplicar dois princípios estruturantes, quais sejam o princípio da igualdade, na qual cada um deve ter direito igual ao mais extenso sistemas de liberdades básicas que sejam compatíveis com um sistema de liberdades idêntico para os demais, bem como pelo princípio da diferença, ou das desigualdades aceitáveis por todos, de forma que as assimetrias econômicas e sociais devem ser distribuídas de forma que, simultaneamente se possa razoavelmente esperar que elas sejam em benefício de todos e decorram de posições e funções às quais todos têm acesso.

Com efeito, as políticas públicas que objetivam estabelecer ações afirmativas vêm sendo instituídas de forma progressiva desde a Constituição Federal de 1988. Tais ações são instrumentos de inclusão do não cidadão, daquele que não participa do Estado Democrático de Direito, do ponto de vista político ou econômico. 
A Defensoria Pública, de acordo com art. $5^{\circ}$ e art. 134 da Constituição Federal, tem como obrigação adotar medidas que implementem os princípios de igualdade material, com ações afirmativas voltadas ao atendimento da população excluída, propiciando a concretização dos ideais explicitados na doutrina da equidade de John Rawls.

Com medidas efetivas realizadas pela Defensoria Pública Brasileira estar-se-á buscando progressivamente cumprir a Constituição Federal, eliminando a perpetuação das desigualdades sociais, consolidando mecanismos objetivando a inclusão de grupos minoritários, excluídos do direito a igualdade material.

\section{REFERÊNCIAS}

ARNSPERGER, Christian; VAN PARIJS, Philippe. Ética econômica e social. Tradução de Nadyr de Salles Penteado e Marcelo Perine. São Paulo: Loyola, 2003.

BOSON, Erik Palácio. A Defensoria Pública como instituição articuladora do direito como padrão de reconhecimento. Revista da Defensoria Pública da União. Brasília, dez. 2013. Disponível em:

$\langle$ http://www.dpu.gov.br/escola/images/revistadpu/revista_06.pdf $>$. Acesso em: 20 set. 2016.

Defensoria Pública da União. Quadro de assistidos. <http://www.dpu.gov.br/images/stories/transparencia/atendimento/Quadro_Atendiment os_Assistidos_Proc_Judiciais_2016_JUN.pdf>. Acesso em: 20 set. 2016.

FERREIRA FILHO, Manoel Gonçalves. Aspectos jurídicos das ações afirmativas. Revista do TST, Brasília, v. 69, n. 2, jul/dez. 2003.

GOMES, Joaquim Benedito Barbosa. Ação Afirmativa \& Princípio Constitucional da Igualdade: o direito como instrumento de transformação social. A experiência dos EUA. Rio de Janeiro: Renovar, 2001.

KERSTENETZKY, Celia Lessa. Desigualdades Justas e igualdade complexa. Lua Nova: Revista de Cultura e Política. n. 47, 1999.

LOIS, Cecilia Caballero. Uma teoria da constituição: justiça, liberdade e democracia em John Rawls. 2001. 370 f. Tese (Doutorado em Direito) - Centro de Ciências Jurídicas, Universidade Federal de Santa Catarina, Florianópolis, 2001.

RAWLS, John. Justiça como eqüidade: uma concepção política, não metafísica. Lua Nova: Revista de Cultura e Política, n. 25, 1992. 
RAWLS, John. Political Liberalism: expanded edition. New York: Columbia University Press, 2005.

RAWLS, John. Uma teoria da justiça. Tradução de Almiro Pisetta e Lenita Maria Rímoli Esteves. São Paulo: Martins Fontes, 2002.

ROCHA, Carmem Lúcia Antunes. Ação afirmativa: o conteúdo democrático da igualdade jurídica. Revista de Informação Legislativa, Brasília, Editora Senado Federal, p. 91, jul/set. 1996.

VITA, Álvaro de. A tarefa prática da filosofia política em John Rawls. Lua Nova: Revista de Cultura e Política, n. 25, 1992. 